\title{
Nicotine induction of theta frequency oscillations in rodent medial septal diagonal band in vitro
}

\author{
Cheng-biao LU ${ }^{1, *}$, Cheng-zhang $\mathrm{LI}^{1}$, Dong-liang $\mathrm{LI}^{1}$, Zaineb HENDERSON ${ }^{2}$ \\ ${ }^{1}$ Department of Physiology and Neurobiology, Xinxiang Medical University, Xinxiang 453003, China; ${ }^{2}$ Institute of Membrane and Sys- \\ tems Biology, Faculty of Biological Sciences, University of Leeds, Leeds LS2 9JT, UK
}

\begin{abstract}
Aim: This study aimed to examine the role of the nicotinic receptor (nAChR) in the generation of theta oscillations (4-12 Hz) in vitro. Methods: Electrophysiological studies were performed on medial septal diagonal band area (MSDB) slices to measure theta oscillation. Immunofluorescence and confocal microscopy studies were carried out to detect $\alpha 4 \mathrm{nAChR}$ and $\beta 2 \mathrm{nAChR}$ subunits in perfused-fixed tissue from VGluT2-GFP and GAD67-GFP transgenic mice.

Results: Application of nicotine to MSDB slices produced persistent theta oscillations in which area power increased in a doseresponsive manner. This activity was inhibited by $\mathrm{GABA}_{\mathrm{A}}$ receptor antagonists and partially by ionotropic glutamate receptor antagonists, indicating the involvement of local GABAergic and glutamatergic neurons in the production of the rhythmic activity. The nicotineinduced theta activity was also inhibited selectively by non- $\alpha 7{ }^{*} \mathrm{nAChR}$ antagonists, suggesting the presence of these receptor types on GABAergic and glutamatergic neuron populations in the MSDB. This was confirmed by immunofluorescence and confocal microscopy studies in transgenic mice in which the GABAergic and glutamatergic neurons express green fluorescent protein (GFP), showing localisation of $\beta 2$ nAChR and $\alpha 4$ nAChR subunits, the most common constituents of non- $\alpha 7^{*}$ nAChRs, in both cell types in the MSDB. Conclusion: Theta activity in the MSDB may be generated by tonic stimulation of non- $\alpha 7{ }^{*}$ AChRs.
\end{abstract}

Keywords: nicotinic receptors; medial septal diagonal band; rhythmogenesis; hippocampal theta rhythm; learning and memory; Alzheimer's disease

Acta Pharmacologica Sinica (2013) 34: 819-829; doi: 10.1038/aps.2012.198; published online 25 Mar 2013

\section{Introduction}

The medial septal diagonal band (MSDB), a rostral extension of the cortically-projecting basal forebrain system, provides major cholinergic and GABAergic projections to the hippocampus ${ }^{[1]}$ and is a key generator of hippocampal theta rhythm (4-12 Hz), believed to serve as an internal timing mechanism for the processing of incoming spatial information $^{[2,3]}$. MSDB receives a cholinergic input from the pedunculopontine nucleus of the brainstem ${ }^{[4,5]}$ and a glutamatergic projection from the supramammillary nucleus (SUM) of the hypothalamus ${ }^{[6]}$

Electrical stimulation of the brainstem reticular formation increases the incidence of rhythmic burst firing in the MSDB, concomitant with a rise in the frequency and amplitude of hippocampal theta activity ${ }^{[7,8]}$. The theta-relevant brainstem reticular activating signals may be therefore relayed to the MSDB via above-mentioned cholinergic and/or glutamatergic

\footnotetext{
* To whom correspondence should be addressed.

E-mail johnlu9000@hotmail.com

Received 2012-08-10 Accepted 2012-12-20
}

inputs which could be involved in causing theta oscillations in the MSDB. These oscillations may then be passed on to the hippocampus.

A major question is whether theta activity is generated in the MSDB in response to tonic activation of its circuits by these afferents, or whether patterned theta frequency input is required $^{[6,9]}$.

Recently, extracellular field oscillations at theta frequency were recorded in the MSDB slices in response to tonic stimulation of ionotropic glutamate receptors, kainate receptors or metabotropic acetylcholine receptors, muscarinic receptors ${ }^{[10-13]}$. The role of the ionotropic acetylcholine receptor, nicotinic receptor (nAChR) in this theta-generating mechanism in the MSDB, however, has yet to be investigated. nAChRs are abundant in the MSDB ${ }^{[14,15]}$, but did not affect evoked and spontaneous postsynaptic responses in the MSDB ${ }^{[15]}$. Our hypothesis therefore is that tonic activation of non- $a 7^{*} \mathrm{nAChRs}$, which do not desensitize as readily as $a 7^{*} \mathrm{nAChRs}{ }^{[16]}$, will produce phasic network activity in the theta frequency range in the MSDB that is mediated by local GABAergic and glutamatergic synaptic circuitry. 


\section{Materials and methods Animals}

All procedures were carried out in accordance with the UK Animals (Scientific Procedures) Act 1986 and with Animal ethics and administrative council of Henan province, China, and all efforts were made to minimise animal suffering and to reduce the number of animals used. Electrophysiological studies were performed on MSDB slices prepared from Wistar rats (male, 3-4 week-old, $n=72$ ). Neuroanatomical observations were also made from perfused-fixed brains of adult heterozygous VGluT2-GFP mice (male or female, 3 week-old, $n=2)$ in which expression of vesicular glutamate transporter 2 (VGluT2), a marker for a subtype of glutamatergic neuron, is linked with expression of green fluorescent protein (GFP; MMRRC.org) and from heterozygous GAD67-GFP ( $\Delta$-neo) knock-in transgenic mice $(n=2)$ in which glutamate decarboxylase 67 (GAD67), a marker for GABAergic neurons, is linked with expression of GFP ${ }^{[17]}$. The VGluT2-GFP mice were bred on a NIH Swiss (Harlan UK) background and GAD67-GFP ( $\Delta$-neo) mice were bred on a C57B16 (Harlan, UK) background. Both types of transgenic mouse were phenotyped at birth by brief observation of fluorescence in the brain (visible through the overlying tissue) under a UV lamp.

For electrophysiology, the rats were anaesthetised by intraperitoneal injection of Sagatal (sodium pentobarbitone, 100 $\mathrm{mg} / \mathrm{kg}$, Rhône Mérieux Ltd, Harlow, UK). When all pedal reflexes were abolished, the animals were perfused intracardially with chilled $\left(5^{\circ} \mathrm{C}\right)$, oxygenated artificial cerebrospinal fluid (ACSF) in which the sodium chloride had been replaced by iso-osmotic sucrose. This ACSF (305 mosmol/L) contained (in mmol/L): 225 sucrose, $3 \mathrm{KCl}, 1.25 \mathrm{NaH}_{2} \mathrm{PO}_{4}, 24 \mathrm{NaHCO}_{3}$, $6 \mathrm{MgSO}_{4}, 0.5 \mathrm{CaCl}_{2}$, and 10 glucose. For extracellular field recording, two sagittal slices $(450 \mu \mathrm{m})$ of rat brain, straddling the midline and containing the MSDB, were cut at $4-5^{\circ} \mathrm{C}$ in the sucrose-ACSF, using a Leica VT1000S vibratome (Leica Microsystems UK, Milton Keynes, UK). For immunocytochemistry, rats and mice were deeply anaesthetised with an ip injection of urethane $(12 \mathrm{~g} / \mathrm{kg})$. After loss of all pedal reflexes the animals were perfused intracardially with $4 \%$ paraformaldehyde in $0.1 \mathrm{~mol} / \mathrm{L}$ phosphate buffer ( $\mathrm{pH} 7.4$ ). The brains were removed and placed in the same fixative for 2-3 $\mathrm{h}$, and then in phosphate buffer overnight at $4{ }^{\circ} \mathrm{C}$. The brains were either used immediately, or immersed overnight in cryoprotectant $(25 \%$ sucrose, $10 \%$ glycerol in $0.05 \mathrm{~mol} / \mathrm{L}$ phosphate buffer) and then frozen with powdered dry ice and stored at $-45^{\circ} \mathrm{C}$.

\section{Electrophysiological recording, data acquisition, and analysis}

For extracellular field recordings, the two MSDB slices were transferred to an interface recording chamber. The slices were maintained at a temperature of $33^{\circ} \mathrm{C}$ and at the interface between ACSF and warm humidified carbogen gas $(95 \%$ $\mathrm{O}_{2}-5 \% \mathrm{CO}_{2}$ ). The ACSF contained (in mmol/L): $126 \mathrm{NaCl}$, $3 \mathrm{KCl}, 1.25 \mathrm{NaH}_{2} \mathrm{PO}_{4}, 24 \mathrm{NaHCO}_{3}, 2 \mathrm{MgSO}_{4}, 2 \mathrm{CaCl}_{2}$, and 10 glucose. The slices were allowed to equilibrate in this medium for $1 \mathrm{~h}$ prior to recording. Both channels of an Axoprobe $1 \mathrm{~A}$ amplifier (Axon Instruments, Union City, CA, USA) were employed for extracellular field recordings, which were made using glass microelectrodes containing ACSF (resistance 2-5 $\mathrm{M} \Omega$ ). Data were band-pass filtered online between $0.5 \mathrm{~Hz}$ and $2 \mathrm{kHz}$ using the Axoprobe amplifier and a Neurolog system NL106 AC/DC amplifier (Digitimer Ltd, Welwyn Garden City, UK). The data were digitized at a sample rate of 5-10 kHz using a CED 1401 plus ADC board (Digitimer Ltd). Electrical interference from the mains supply was eliminated from extracellular recordings online with the use of $50 \mathrm{~Hz}$ noise eliminators (HumBug; Digitimer Ltd).

Data were analyzed off-line using software from Spike 2 (CED, Cambridge, UK). Power spectra were generated to provide a quantitative measure of the frequency components in a stretch of recording, where power, a quantitative measure of the oscillation strength, was plotted against the respective frequency. Power spectra were constructed for 30-60 s epochs of extracellular field recordings using a fast Fourier transform algorithm provided by Spike2. The parameters used for measuring the oscillatory activity in the slice were peak frequency $(\mathrm{Hz})$ and area power $\left(\mu \mathrm{V}^{2}\right)$. In the current study, area power was equivalent to the computed area under the power spectrum between the frequencies of 4 and $14 \mathrm{~Hz}^{[18]}$.

All statistical tests were performed using SigmaStat software (SPSS Inc, California, USA). Results are expressed as mean \pm standard error of mean, unless indicated otherwise. Statistical significance for comparison between two groups or between three groups was determined using tests described in the text or in the figure legends, as appropriate. Measures were considered statistically significant if $P<0.05$.

\section{Drugs used for electrophysiology}

All standard reagents, except where indicated, were obtained either from Sigma-Aldrich (UK) or VWR International (Lutterworth, UK). D-(-)-2-amino-5-phosphonopentanoic acid (D-AP5), bicuculline methochloride, SR 95531 hydrobromide (GABAzine), and 2,3,-dioxo-6-nitro-1,2,3,4-tetrahydrobenzo[f] quinoxaline-7-sulphonamide (NBQX) were purchased from Tocris Cookson Ltd (Bristol, UK). Atropine sulphate, choline, dihydro- $\beta$-erythroidine (DH $\beta E)$, methyllycaconitine (MLA), nicotine sulphate, and agents for the ACSF solution were obtained from Sigma-Aldrich (UK). Stock solutions, at $10^{3}$ of the working concentration, were made up in water, except for NBQX which was dissolved in dimethylsulphoxide and stored in individual aliquots at $-45^{\circ} \mathrm{C}$. Working solutions were prepared freshly on the day of the experiment.

\section{Immunofluorescence}

To confirm electrophysiological observations, immunocytochemical staining was made for the a $4 \mathrm{nAChR}$ and $\beta 2$ $n A C h R$ subunits in perfused-fixed tissue from VGluT2-GFP and GAD67-GFP transgenic mice. Due to weakened levels of GFP-fluorescence in the VGluT2-GFP mice after fixation, the GFP in these specimens was enhanced by dual labelling for GFP immunofluorescence using an antibody to GFP. Sections were cut at $50 \mu \mathrm{m}$ in the coronal plane using a Leica VT1000S 
vibratome (Leica, Microsystems UK, Milton Keynes, UK). Unless stated otherwise, all steps were carried out at room temperature and with gentle agitation of the sections. Optimal results for antigen retrieval were obtained by treatment of the sections with ethanol and methanol solutions prior to carrying out the immunocytochemical steps ${ }^{[15]}$. This antigen retrieval process was found to reduce the background staining that is a problem with antibodies to $\mathrm{nAChR}$ subunits and which contributes to non-specific staining observed in knockout mice for the $\mathrm{nAChR}$ subunits ${ }^{[19]}$. Sections were washed in $30 \%, 50 \%, 70 \%, 90 \%$, and $100 \%$ ethanol for 3-4 min each, and then placed in $100 \%$ methanol at $-20^{\circ} \mathrm{C}$ for $5 \mathrm{~min}$. The sections were then taken through descending solutions of ethanol, and then washed in $0.1 \%$ Triton in phosphate-buffered saline $(\mathrm{pH}$ 7.4). The sections were then incubated for $1 \mathrm{~h}$ in $2 \%$ bovine serum albumin. Sections were placed in single or double antibody solutions in $2 \%$ bovine serum albumin and $0.4 \%$ sodium azide and incubated in these solutions for $1-2 \mathrm{~d}$ at $4{ }^{\circ} \mathrm{C}$. The primary antibodies were omitted in controls, and sections from the hippocampus were included as positive controls for staining for the $\mathrm{a} 4$ and $\beta 2 \mathrm{nAChR}$ receptor subunits. Primary antibody to the a $4 \mathrm{nAChR}$ subunit (rabbit polyclonal antibody, Santa Cruz Biotechnology) was used at a concentration of $1 / 600$. Antibodies for the $\beta 2 \mathrm{nAChR}$ receptor were used at these concentrations: 1/600 (rabbit polyclonal antibody, Santa Cruz Biotechnology, Heidelberg), 1/1000 (rat monoclonal antibody, mAb290, gift from Dr JM Linstrom, University of Pennsylvania), and 1/75 (rat monoclonal mAb270, Sigma-Aldrich). In VGluT2-GFP mice, the antibodies to the nAChR subunits were used in combination with $1 / 2000$ chicken polyclonal anti GFP antibody (Abcam PLC, Cambridge, UK). Following several washes over the period of $1 \mathrm{~h}$, the sections were incubated for 2-3 h in 1:1000 donkey secondary antibody against rabbit IgG or rat IgG conjugated to Alexa Fluor 594, on its own or combined with 1/1000 donkey anti chicken IgG conjugated to FITC (Invitrogen Life Technologies, Paisley). Sections were washed several times and mounted on "polysine" slides (Fisher Scientific UK Ltd, Loughborough, UK) and embedded in Vectamount (Vector Laboratories Ltd, Peterborough, UK). The sections were then viewed with a Zeiss LSM 510 Meta confocal microscope (Zeiss, Welwyn Garden City, UK). Stacked confocal images were taken at random through the rostro-caudal axis of the MSDB and of other areas of the brain and were analysed using the Zeiss LSM Image Browser program.

\section{Results}

\section{Nicotine induces oscillatory activity in MSDB slices}

A previous study demonstrated that the theta oscillatory activity can be recorded in midline of $\mathrm{MSDB}^{[11]}$, this observation was confirmed in this study using two roving electrodes $(n=8)$. Therefore, we performed our recording in the midline of MSDB. Bath application of $0.025-5 \mu \mathrm{mol} / \mathrm{L}$ nicotine to MSDB slices induced persistent oscillatory field activity, an example of nicotine $(250 \mathrm{nmol} / \mathrm{L})$ induced activity was shown in Figure 1A. This activity occurred at frequencies that ranged from
4.8 to $8.6 \mathrm{~Hz}$ (average: $5.8 \pm 0.6 \mathrm{~Hz}, n=47$ ), as indicated by the power spectra (Figure 1B) and autocorrelograms of the activity (Figure 1C). The induced oscillatory field activity was also often accompanied by fast downwards signals, interpreted as extracellular action potentials recorded from one or more neuron cell bodies lying fortuitously close to the recording electrode (Figure 1A). Area power $(4-12 \mathrm{~Hz})$ of the oscillatory activity reached a plateau 10-20 min after application of the nicotine and remained stable for at least $30 \mathrm{~min}$ thereafter (Figure 1D). At a dose of $0.01 \mu \mathrm{mol} / \mathrm{L}$, nicotine had no significant effect on area power, but upon application of doses of nicotine ranging from $0.025-0.5 \mu \mathrm{mol} / \mathrm{L}$, area power increased in a dose-responsive manner (Figure 1E-1G). There was a statistically significant difference in the mean power among the treatment groups (ANOVA; $P<0.01$ ), but there was no significant difference in oscillation frequency between the different effective concentrations of nicotine applied (Figure 1F).

lonotropic glutamate and GABA receptors mediate nicotineinduced oscillatory activity in the MSDB slice

Oscillatory activity induced by nicotine $(250 \mathrm{nmol} / \mathrm{L})$ was examined after addition of the ionotropic glutamate receptor antagonists D-AP5 $(50 \mu \mathrm{mol} / \mathrm{L})$ and NBQX $(20 \mu \mathrm{mol} / \mathrm{L})$ or the ionotropic $\mathrm{GABA}_{\mathrm{A}}$ receptor antagonists GABAzine (10 $\mu \mathrm{mol} / \mathrm{L})$ and bicuculline $(20 \mu \mathrm{mol} / \mathrm{L})$.

Addition of NBQX largely reduced nicotine-induced oscillatory activity (Figure 2A), but D-AP5 had no substantial effect on nicotine-induced oscillatory activity (Figure 2B). Substantial reduction of the nicotine-induced oscillatory activity was achieved with GABAzine (Figure 2C). The results so far therefore indicate that tonic activation of $\mathrm{nAChRs}$ is able to generate theta frequency-like activity in MSDB slices, and that this activity is mediated by both ionotropic glutamatergic and GABAergic receptor neurotransmission, ie suggesting involvement of local GABAergic and glutamatergic circuitry in the nicotine-induced oscillatory activity. Our result showed AMPA receptor antagnoist NBQX but not NMDA receptor antagonist D-AP5 largely reduced nicotine induced theta oscillation. This is in agreement with previous findings that kainate induced theta oscillations were not mediated by NMDA receptor activation (Garner et al 2005), suggesting that nicotine and kainate activate similar local network circuitry involving in AMPA receptor activation.

\section{Nicotine-induced oscillatory activity in the MSDB slice is mediated by non- $\alpha 7{ }^{*}$ AChR subtypes}

Oscillatory activity induced in the MSDB slice by $250 \mathrm{nmol} / \mathrm{L}$ nicotine was blocked by $0.3 \mu \mathrm{mol} / \mathrm{L}$ dihydro- $\beta$-erythroidine $(\mathrm{DH} \beta \mathrm{E})$, which in low concentrations is an antagonist for the $a 4 \beta 2 \mathrm{nAChR}^{[20]}$ (Figure 3A-3D). Pretreatment of the slices with $0.3 \mu \mathrm{mol} / \mathrm{L} \mathrm{DH} \beta \mathrm{E}$ alone had no significant effect $(3.4 \% \pm 5.3 \%)$ on area power of the baseline activity, and addition of $250 \mathrm{nmol} / \mathrm{L}$ nicotine caused a small but non-significant increase in the area power $(16 \% \pm 9.7 \%, P>0.05$ vs DH $\beta E$ alone, Figure 3E). Substitution of the bathing medium with $250 \mathrm{nmol} / \mathrm{L}$ nicotine significantly increased area power by 

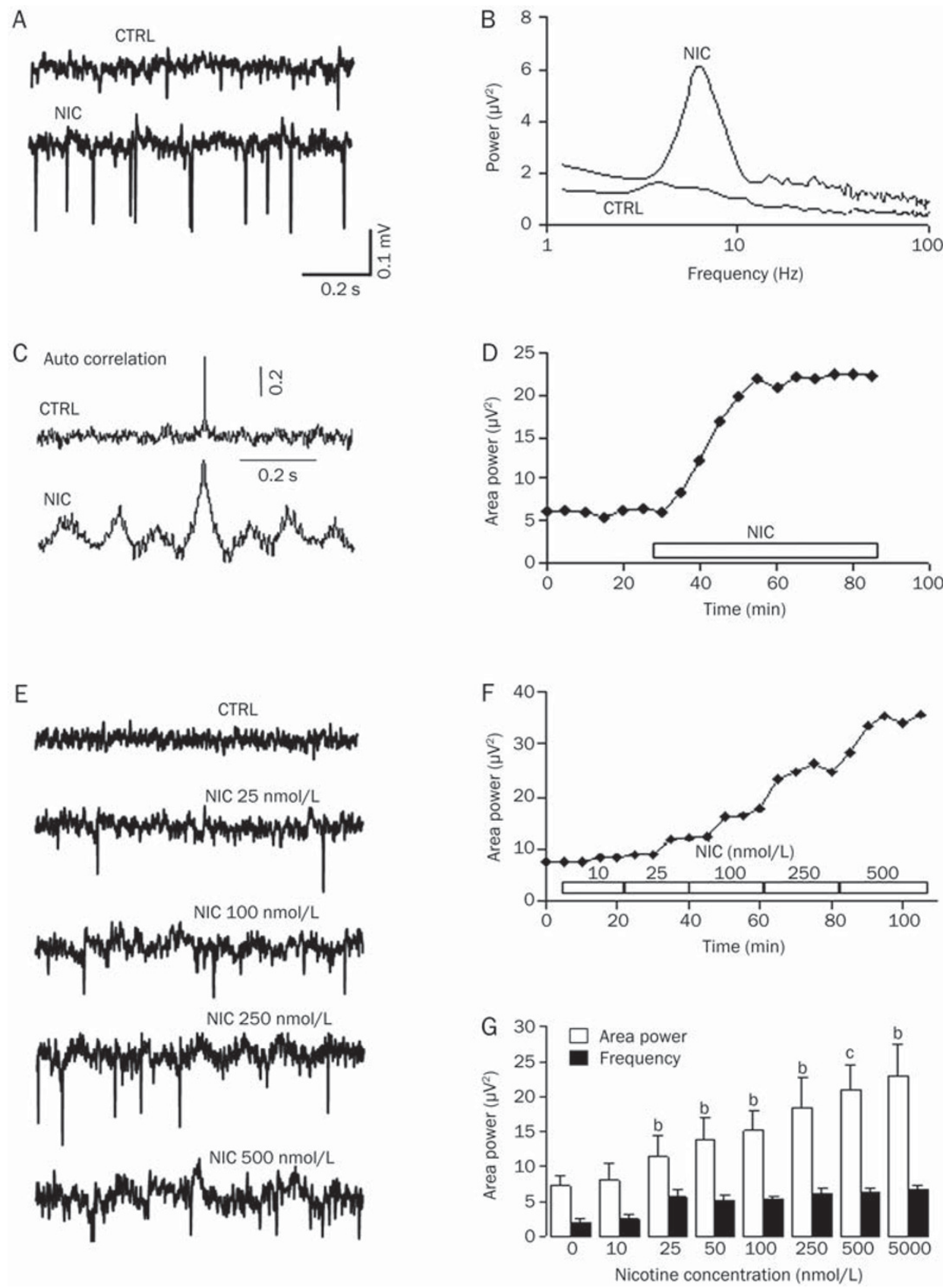

Figure 1. Nicotine induces oscillatory activity in MSDB slices. A) Representative extracellular recordings of oscillatory field activity before and after application of nicotine (250 nmol/L) to an MSDB slice. B) Corresponding power spectra of episodes of the oscillations shown in A. C) Corresponding autocorrelograms of the oscillations shown in A. D) Time course of the action of $250 \mathrm{nmol} / \mathrm{L}$ nicotine on area power (4-14 $\mathrm{Hz})$ corresponding to the experiment shown in A. E) Representative extracellular recordings of oscillatory field activity before and after application of increasing concentrations of nicotine to an MSDB slice. F) Example time course of the effects of application of increasing concentrations of nicotine on area power (4-14 $\mathrm{Hz}$ ) in an MSDB slice. G) Change in area power $(4-14 \mathrm{~Hz})$ with concentrations of nicotine; results were pooled from experiments in which successive administration of higher doses of nicotine was made in the same slice, or by application of various concentrations of nicotine to different slices ( $n=19-20$ for $50 \mathrm{nmol} / \mathrm{L}$ and $500 \mathrm{nmol} / \mathrm{L}$ groups. $n=12$ for $5 \mu \mathrm{mol} / \mathrm{L}$ groups and $n=6-7$ slices for the remaining groups. ${ }^{b} P<0.05$, ${ }^{c} P<0.01$, for area power in comparison with control, ANOVA, post hoc Student-Newman-Keuls test). There was no significant difference in oscillation frequency between concentrations of nicotine applied (ANOVA, post hoc Student-Newman-Keuls test).

$47 \% \pm 9.6 \%(n=11, P<0.05$ vs DH $\beta E$ with nicotine, repeated measures ANOVA on rank; Figure 3E). This work suggests that the induction of persistent oscillatory activity in MSDB slices by bath-applied nicotine is mediated by activation of non$a 7^{*}$ nAChRs. Coupled with the results described in the previous section, this is in consistent with our recent work showing 



Figure 2. Ionotropic glutamate and GABA receptors mediate nicotine-induced oscillatory activity in the MSDB slice. A1) Time course of the effects of the addition of $250 \mathrm{nmol} / \mathrm{L}$ nicotine, followed by $20 \mu \mathrm{mol} / \mathrm{L}$ NBQX on area power of oscillatory activity in an MSDB slice. A2) Corresponding power spectra of the episodes of the oscillations shown in A1. B1) Example time course of the effects of the addition of 250 nmol/L nicotine, followed by D-AP5 (50 $\mathrm{mmol} / \mathrm{L})$ on area power of oscillatory activity in an MSDB slice. B2) Corresponding power spectra of the episodes of the oscillations shown in B1. C1) Example time course of the effects of the addition of $250 \mathrm{nmol} / \mathrm{L}$ nicotine, followed by $10 \mu \mathrm{mol} / \mathrm{L}$ GABAzine on area power of oscillatory activity in an MSDB slice. C2) Corresponding power spectra of the episodes of the oscillations shown in C1. D) Effects of NBQX (20 $\mu$ mol/L), D-AP5 (50 $\mu \mathrm{mol} / \mathrm{L})+\mathrm{NBQX}(20 \mu \mathrm{mol} / \mathrm{L})$, or of bicuculline $(20 \mu \mathrm{mol} / \mathrm{L})$ or GABAzine $(10 \mu \mathrm{mol} / \mathrm{L})$ on theta oscillatory activity induced by $250 \mathrm{nmol} / \mathrm{L}$ nicotine $(n=7$ all groups. ${ }^{b} P<0.05,{ }^{c} P<0.01$ vs NIC. Student $t$ test).

the presence of somatodendritic, non- $\alpha 7^{*} \mathrm{nAChRs}$ receptors on GABAergic neurons in the MSDB ${ }^{[15]}$.

There is no significant involvement of $\alpha 7{ }^{*}$ nAChRs in nicotineinduced oscillatory activity in the MSDB slice

The effects of $100 \mathrm{nmol} / \mathrm{L}$ methyllycaconitine (MLA), an $a 7^{*} \mathrm{nAChR}$ antagonist, was tested on nicotine-induced oscillatory activity in the MSDB slice. MLA did not have a significant effect on oscillatory activity pre-induced by $250 \mathrm{nmol} / \mathrm{L}$ nicotine $(n=4, P>0.05$, paired $t$-test, data not illustrated). Pretreatment of slices with MLA did not significantly affect basal field activity (Figure 4A2, 4A3), but application of $250 \mathrm{nmol} / \mathrm{L}$ nicotine in the presence of MLA caused a significant increase in the area power (Figure 4A). Substitution of medium with $250 \mathrm{nmol} / \mathrm{L}$ nicotine increased the area power further, but this was not significantly different from the previous (Figure 4A). To further examine the possible involvement of $\alpha 7^{*} n A C h R$ in nicotine-induced oscillatory activity in the MSDB, the effects of the bath application of choline, a selective $a 7^{*} \mathrm{nAChR}$ agonist was examined. Choline $(5 \mathrm{mmol} / \mathrm{L})$ on its own did not induce a significant level of oscillatory activity in the MSDB slice (Figure 4B), but substitution of the choline with $500 \mathrm{nmol} / \mathrm{L}$ nicotine produced robust oscillatory field activity indicating that the lack of effect of the choline was not due to a defective slice preparation (Figure $4 \mathrm{~B}$ ). These results suggest that $a 7^{*} \mathrm{nAChRs}$ do not play a significant role in the induction of persistent oscillatory activity in MSDB slices by bath-applied nicotine.

Immunoreactivity for the $\alpha 4 \mathrm{nAChR}$ and $\beta 2$ subunits is present in GABAergic and glutamatergic neurons in the MSDB of GFP transgenic mice

To confirm the presence of non- $\alpha 7^{*} n A C h R$ subtypes on GABAergic and glutamatergic neurons in the MSDB, immunocytochemical staining was carried out for the a $4 \mathrm{nAChR}$ and $\beta 2 \mathrm{nAChR}$ subunits, the most common constituents of non- 

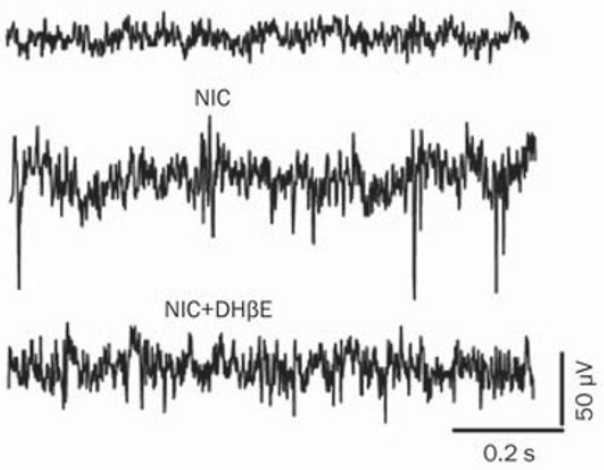

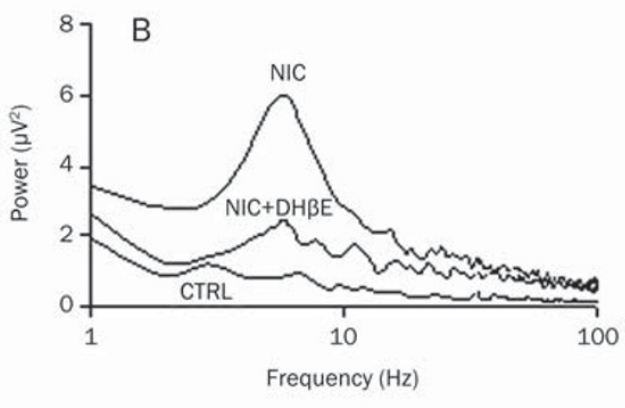

D

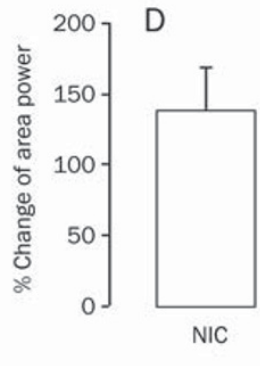

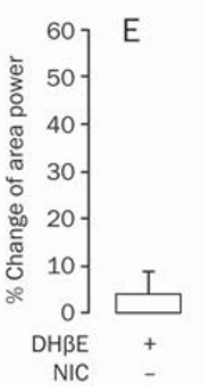

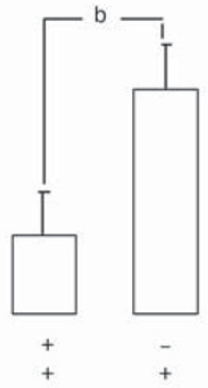

Figure 3. Nicotine-induced oscillatory activity in the MSDB slice is mediated by non- $\alpha 7 *^{*}$ AChR subtypes, some of which are present on glutamatergic neurons. A) Representative traces of nicotine-induced oscillations showing that these oscillations are blocked by $0.3 \mu \mathrm{mol} / \mathrm{L} \mathrm{DH} \beta \mathrm{E}$. $\mathrm{B}) \mathrm{Corresponding}$ power spectra of episodes of the oscillations shown in A. C) Example time course of the action of $250 \mathrm{nmol} / \mathrm{L}$ nicotine, followed by $0.3 \mu \mathrm{mol} / \mathrm{L} \mathrm{DH} \beta \mathrm{E}$ on area power, for the experiment shown in A. D) Percentage change in area power with respect to control after addition of $250 \mathrm{nmol} / \mathrm{L}$ nicotine, followed by $0.3 \mu \mathrm{mol} / \mathrm{L} \mathrm{DH \beta E}\left({ }^{b} P<0.05, n=5\right.$, Student $t$-test). E) Percentage change in area power with respect to control after addition of $0.3 \mu \mathrm{mol} / \mathrm{L}$ $\mathrm{DH} \beta \mathrm{E}$, followed by $250 \mathrm{nmol} / \mathrm{L}$ nicotine, followed by washout of the $\mathrm{DH} \beta \mathrm{E}$.

$a 7^{*} \mathrm{nAChR}$ subtypes in the CNS. This work was performed on tissue from GAD67-GFP and VGluT2-GFP mice, to allow for identification of the GABAergic and glutamatergic neuronal populations in the MSDB by the presence of GFP. No significant labelling was observed in the tissue upon omission of the primary antibodies (Figure 5A). As a positive control, subunit labelling was observed in interneurons of CA1 of the hippocampus but not in the pyramidal cell layer (Figure 5B), in keeping with the electrophysiological studies that have shown that a proportion of interneurons in CA1 possess non$a 7^{*} n A C h R-l i k e$ responses to puffed $A h^{[21]}$. No labelling of the hippocampal interneurons was present when the primary antibody was omitted (Figure 5C). In the MSDB, the a 4 nAChR subunit was present in GAD67-GFP neurons (Figure 5D) and in VGluT2-GFP neurons (Figure 5E). Similar observations were also made for the $\beta 2 \mathrm{nAChR}$ subunit (example not illustrated). In GAD67-GFP transgenic mice, the total neuronal number for a 4 and $\beta 2 \mathrm{nAChR}$ subunit antibody group is 226 and 343, respectively (Figure 5F1). The percentage of positive staining neurons for a $4 \mathrm{nAChR}$ antibody only (GAD67-GPF negative), GAD67-GFP only (nAChR staining negative) and a4 nAChR antibody and GAD67-GFP is $14 \%, 32 \%$, and $54 \%$, respectively (Figure 5F2, open bars). The similar results were obtained for $\beta 2 \mathrm{nAChR}$ antibody staining (Figure 5F1, 5F2, filled bars). The percentage of the neurons with both nAChR antibody and GAD67-GFP positive over all GAD67-GFP positive neurons is $63 \%$ for both a $4 \mathrm{nAChR}$ and $\beta 2 \mathrm{nAChR}$ antibody groups.

In VGluT2-GFP transgenic mice, the total number of neurons for $\alpha 4$ and $\beta 2 \mathrm{nAChR}$ subunit antibody groups is 140 and 255, respectively (Figure 5G1). The percentage of positive staining neurons for a4 nAChR antibody only (VGlut2-GFP negative), VGluT2-GFP only (nAChR staining negative) and a 4 nAChR antibody and VGluT2-GFP is $56 \%, 24 \%$, and $20 \%$, respectively (Figure 5G2, open bars). The percentage of positive staining neurons for $\beta 2 \mathrm{nAChR}$ antibody only (VGluT2-GFP negative), VGluT2-GFP only (nAChR staining negative) and $\beta 2 \mathrm{nAChR}$ antibody and VGluT2-GFP is $60 \%, 30 \%$, and $10 \%$, respectively (Figure 5G2, filled bars). The percentage of neurons with both nAChR antibody and VGluT2-GFP positive over all VGlut2GFP positive is $45 \%$ for a $4 \mathrm{nAChR}$ and $25 \%$ for $\beta 2 \mathrm{nAChR}$ subunit. Therefore, quantification of the labelling indicated both GABAergic and glutamatergic neuron types were labelled for each of the a $4 \mathrm{nAChR}$ and the $\beta 2 \mathrm{nAChR}$ subunits (Figure 5F, $5 \mathrm{G})$. These results, coupled with the pharmacological data, suggest that activation of non- $7^{*} \mathrm{nAChRs}$ by nicotine in the MSDB may have a effect on both GABAergic and glutamatergic circuitry in the MSDB slice preparation. 
A1
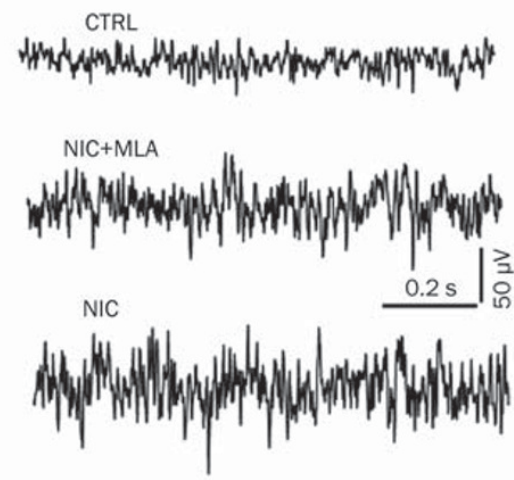

B1 CTRL

CHOLINE

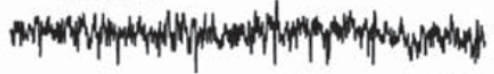
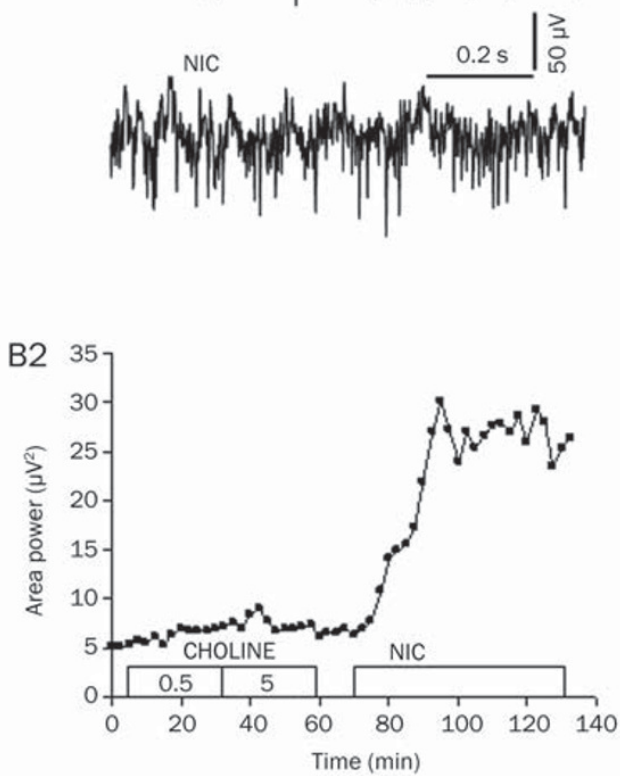

B3

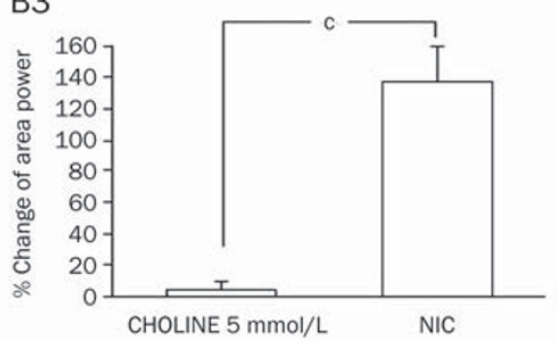

Figure 4. There is no significant involvement of $\alpha 7^{*} n A C h R s$ in nicotine-induced oscillatory activity in the MSDB slice. A1) Example traces of nicotineinduced oscillatory activity in the presence of $100 \mathrm{nmol} / \mathrm{L}$ methyllycaconitine (MLA), a reversible $\alpha 7{ }^{*} \mathrm{nAChR}$ antagonist, and after removal of the MLA and retention of the nicotine. A2) Example time course of the nicotine-induced oscillatory activity in the presence of MLA and after washout of the MLA and in the presence of nicotine. A3) Percentage changes in area power with respect to control after addition of MLA, followed by $250 \mathrm{nmol} / \mathrm{L}$ nicotine, followed by washout of the MLA. There was a significant difference of area power between application MLA and then nicotine, but not between the latter and the area power in the presence of nicotine after washout of the MLA ( $n=5 .{ }^{b} P<0.05$, repeated measures ANOVA). B1) Example traces of oscillatory field activity firstly in the presence of $5 \mathrm{mmol} / \mathrm{L}$ choline, a specific $\alpha 7{ }^{*} \mathrm{nAChR}$ agonist, followed by washout of the choline and application of $250 \mathrm{nmol} / \mathrm{L}$ nicotine. B2) Example time course of oscillatory field activity firstly in the presence of choline, followed by washout of the choline and application of 250 $\mathrm{nmol} / \mathrm{L}$ nicotine. B3) Percentage changes in area power with respect to control after addition of $5 \mathrm{mmol} / \mathrm{L}$ choline, followed by washout of the choline and application of $250 \mathrm{nmol} / \mathrm{L}$ nicotine. The area power generated by choline was not significantly different from the control, but application of nicotine caused an increase in area power that was significantly different from both control and the choline-induced activity $\left(n=7\right.$. ${ }^{\mathrm{c}} P<0.01$, repeated measures ANOVA).

\section{Discussion}

The current study showed that bath-application of nicotine at nanomolar concentration is able to elicit persistent and doseresponsive oscillatory activity in the MSDB slice, and within the in vivo theta frequency range of $4-12 \mathrm{~Hz}$. This activity was similar in appearance and magnitude to that produced by bath application of nanomolar concentrations of kain- ate to the MSDB slice ${ }^{[11]}$ and which has been correlated with the presence of compound inhibitory synaptic potentials at theta frequency ${ }^{[10]}$. Although it has been shown previously that application of nanomolar concentrations of kainate to hippocampal slices elicits oscillatory activity in the gamma frequency range ${ }^{[22]}$, application of same concentrations of kainate to MSDB slices induces oscillatory activity in the theta 

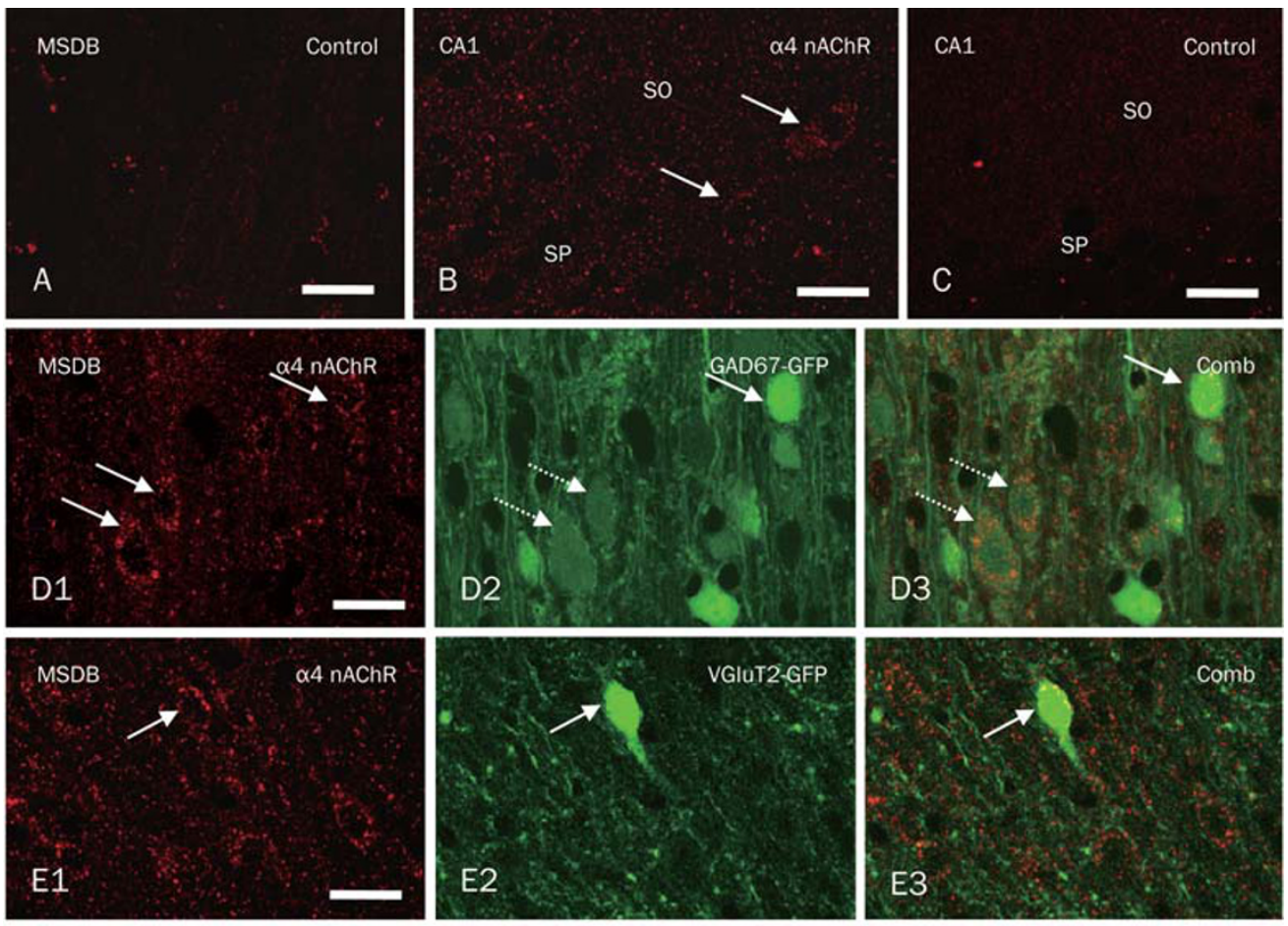

F1

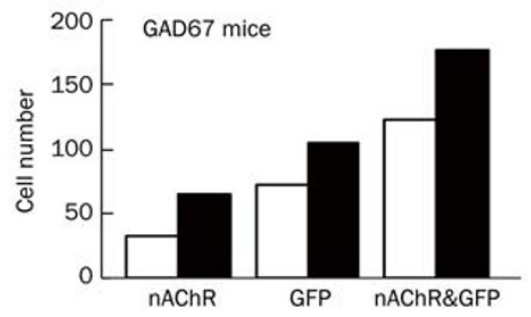

G1

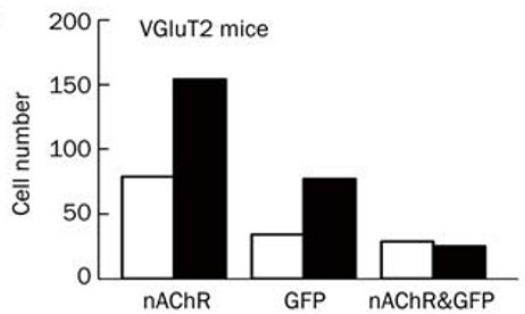

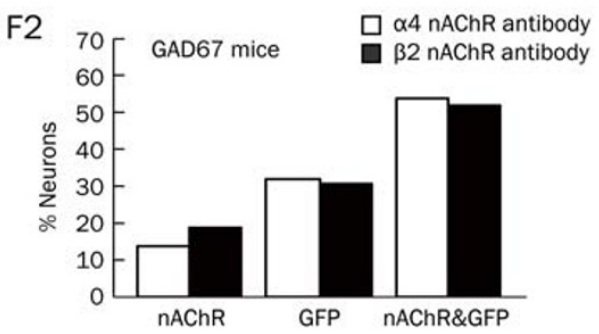

G2

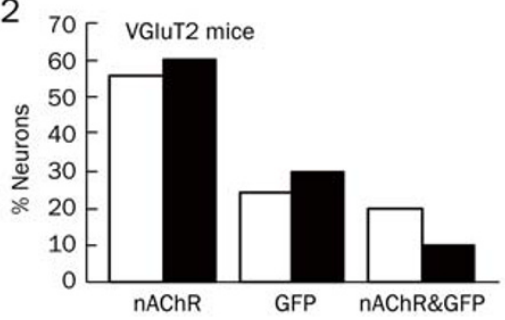

Figure 5. Immunoreactivity for the $\alpha 4$ and $\beta 2 \mathrm{nAChR}$ subunits is present in GABAergic and glutamatergic neurons in the MSDB of GFP transgenic mice. A) Negative control, showing lack of immunofluorescence in MSDB from VGluT2-GFP mouse, after omission of the primary antibody to the $\alpha 4$ nAChR subunit in the staining protocol. B) Positive control, showing the presence of immunofluorescence for the $\alpha 4$ nAChR subunit in hippocampal interneurons (arrowed) in the striatum oriens (SO), but not in the pyramidal neurons of the striatum pyramidale (SP) of the CA1 region in the hippocampus from the VGluT2-GFP mouse. C) Negative control for (B), showing lack of immunofluorescence in CA1 from hippocampus of VGluT2-GFP mouse, after omission of the antibody to the $\alpha 4 \mathrm{nAChR}$ subunit in the staining protocol. D) Dual fluorescence confocal image showing presence of the $\alpha 4$ nAChR subunit in GFP+ve soma (arrowed) and GFP-ve soma (arrowed, dashed arrows) in the MSDB of the GAD67-GFP mouse. E) Dual fluorescence confocal image showing presence of the $\alpha 4$ nAChR subunit in GFP+ve soma (arrowed) and GFP-ve soma (arrowed) in the MSDB of the VGluT2-GFP mouse. F) Proportions of MSDB neurons showing labelling for the $\alpha 4$ or $\beta 2$ nAChR subunits in GAD67-GFP; F1) the total number of positive staining neurons for $\alpha 4$ and $\beta 2$ nAChR subunit antibody groups in GAD67-GFP. F2) The percentage of positive staining neurons for $\alpha 4$ and $\beta 2$ nAChR subunit in GAD67-GFP. The open bars refer to the staining for the $\alpha 4$ nAChR subunit, and the filled bar charts refer to staining for the $\beta 2$ nAChR subunit. G) Proportions of MSDB neurons showing labelling for the $\alpha 4$ or $\beta 2$ nAChR subunits in VGluT2-GFP mice. G1) the total number of positive staining neurons for $\alpha 4$ and $\beta 2$ nAChR subunit antibody groups in VGlut2-GFP. G2) The percentage of positive staining neurons for $\alpha 4$ and $\beta 2$ nAChR subunit in VGluT2GFP. 
frequency range $\mathrm{e}^{[11]}$. The kainate-induced rhythm reported by Garner et al was not affected by either muscarinic or nicotinic antagonists and the activity reported in this study was not completely blocked by the AMPA/kainate blocker which suggest that different agonists may generate different networks of neurons to produce the same output such as theta oscillations $^{[11]}$. This has been shown to be the case in the hippocampus for carbachol and DHPG (a selective agonist of group I metabotropic glutamate receptors)-evoked gamma frequency oscillations ${ }^{[23]}$. Therefore, induction of theta rhythm is likely determined by local neuronal circuits activated by specific receptor agonists in the MSDB. In the current study it was likely that the oscillatory field activity induced by nicotine in the MSDB slice represents network oscillations produced by activation of local GABAergic and glutamatergic circuitry, since the oscillatory activity was inhibited by ionotropic GABAergic and partially inhibited by glutamatergic receptor antagonists. This is an important conclusion about the collaboration between glutamatergic and GABAergic neurons in the generation of theta oscillatory activity in the MSDB that was not so easy to test in the previous experiments involving kainate. Compared with kainate induced theta oscillation, the extracellular oscillatory field activity induced by nicotine in the MSDB was of relatively small amplitude, and is most likely due to the lack of neuronal array in parallel as they are in the hippocampus. Nevertheless, oscillatory activity induced locally by carbachol in the MSDB in an in vitro septohippocampal preparation has been shown to be powerful enough to drive theta activity in the attached hippocampus ${ }^{[13]}$.

\section{Nicotine-induced theta activity in the MSDB slice is mediated by non- $\alpha 7$ * nAChRs}

The results of the current study indicated a clear involvement of non- $\alpha 7^{*} \mathrm{nAChRs}$, probably of the $\alpha 4 \beta 2^{*} \mathrm{nAChR}$-type rather than $\alpha 7^{*} \mathrm{nAChRs}$, in mediating nicotine-induced rhythmogenic activity in the MSDB in vitro. Immnunofluorescence and the application of pharmacological agents to the MSDB slices also suggested the presence of $\alpha 4 \beta 2^{*} n A C h R s$ on local GABAergic and glutamatergic neurons in MSDB, and with possibly greater abundance of the receptors on the GABAergic neurons. This is in agreement with previous electrophysiology and immunocytochemical studies suggesting the presence of non- $\alpha 7^{*} \mathrm{nAChRs}$ on GABAergic neurons ${ }^{[15,24]}$ and electrophysiological studies indirectly indicating the presence of these receptors on glutamatergic neurons in the $\mathrm{MSDB}^{[14]}$. In the hippocampus the majority of GABAergic interneurons express postsynaptic $\alpha 7^{*} n A C h R s^{[20]}$, whilst in the MSDB this receptor subtype seems to be confined mainly to the cholinergic neurons, which do not apparently take part in conventional synaptic transmission ${ }^{[15]}$. Non- $7^{*} n A C h R s$ desensitise less readily than $\alpha 7^{*} \mathrm{nAChRs}$, and in MSDB the former respond to concentrations as high as $20 \mu \mathrm{mol} / \mathrm{L}$ with apparently little desensitisation $^{[14]}$. It is likely therefore that the effect of nicotine on promoting theta frequency activity in the MSDB, and its apparent ineffectiveness in the hippocampus ${ }^{[25]}$ is related to the different desensitising properties of the predominant
nAChR subtypes present in these two areas. These studies, however, do not preclude the contribution of presynaptic receptors in promoting the nicotine-induced oscillatory activity in the MSDB slice, but so far little is known about the presynaptic distribution of nAChRs in the MSDB and which specific neuron cell types they are associated with.

Inhibition of ionotropic GABAergic transmission does not promote paroxysmal activity in the MSDB in the presence of nicotine

In our study we have shown that $\mathrm{GABA}_{\mathrm{A}}$ receptor antagonists such as bicuculline inhibit nicotine-induced oscillatory activity in the MSDB slice. In such preparations exposed to other agonists such as carbachol, the addition of bicuculline promotes paroxysmal theta activity, interpreted as being due to release of intrinsic glutamatergic neurons from local inhibition ${ }^{[12]}$. These contrasting results may reflect differences in the proportional distribution of $\mathrm{nAChR}$ and muscarinic receptors on GABAergic and glutamatergic neurons in the MSDB. Certainly with respect to non- $7^{*} \mathrm{nAChRs}$, we have shown by immunocytochemistry that these appear to be more abundant on the GABAergic rather than the glutamatergic neurons of the MSDB. These studies therefore suggest a possible therapeutic value for specific $\mathrm{nAChR}$ agonists in restoring some of the effects of a basal forebrain cholinergic innervation depleted in Alzheimer's disease. However, it is still not known whether the cholinergic drive to the MSDB arises from the intrinsic cholinergic neurons, or those from the pedunculopontine nucleus, which are not affected in Alzheimer's disease.

\section{Nicotine promotes oscillatory field activity but not rhythmic burst firing in the MSDB in vitro}

The hippocampal theta rhythm in vivo is tied in which the presence of rhythmic burst firing activity recorded by extracellular electrodes in the midline regions of the $\mathrm{MSDB}^{[8,26]}$. Extrinsic, non-cortical inputs to the septum seem to control the incidence of the burst firing ${ }^{[7-9]}$, but there has been controversy as to whether this activity in the MSDB is generated intrinsically by tonic input or is driven by theta-patterned input from elsewhere, most notably the SUM ${ }^{[6]}$. Evidence for the intrinsic ability of the MSDB to generate theta activity is suggested by the retention of rhythmic burst firing at theta frequency in the MSDB following undercutting the septum, or lesion to the fornix or $\mathrm{SUM}^{[27-29]}$. Spontaneous rhythmic burst firing at 3 $\mathrm{Hz}$ was also reported to occur in the MSDB slice of the ground squirrel and to be mediated by activation of nAChRs ${ }^{[30]}$, but such activity has not been described previously in rodent MSDB in vitro.

Basal forebrain glutamatergic neurons may play a role in relaying external rhythmogenic inputs to the MSDB

The results so far indicate that tonic activation of nAChRs is able to generate theta frequency-like activity in MSDB slices, and that this activity is mediated by both ionotropic glutamatergic and GABAergic receptor neurotransmission, ie suggesting involvement of local GABAergic and glutamatergic 
circuitry in the nicotine-induced oscillatory activity. It is noteworthy that nicotine induced oscillations were reduced but not completely abolished by the ionotropic glutamate receptor blocker, NBQX, suggesting that glutamatergic system enhances the theta frequency activity but is not essential for its generation. The lack of robustness of rhythmic burst firing activity in the MSDB in vitro also suggests the importance of a patterned theta component from elsewhere that is removed from the conventional slice preparation ${ }^{[31]}$. Whether these components arise directly from the SUM or from mediumrange connections from nearby regions that are excluded from the slice preparations is not known. This is especially important with respect to the role of the newly discovered glutamatergic neurons in the basal forebrain area in which the MSDB is embedded. Although the septal region is seen as a relay station between its ascending inputs and the hippocampus, it is of interest that the non-cortical inputs to the MSDB that arise from the SUM ${ }^{[6,32-34]}$, dorsolateral nucleus of the lateral septum ${ }^{[35,36]}$ and the pedunculopontine nucleus of the brainstem ${ }^{[37]}$ terminate in many regions lateral and caudal to the MSDB, some of which host the newly discovered populations of VGluT2-GFP-positive neurons ${ }^{[14,38-40]}$. This suggests that the basal forebrain region is a highly complex structure and that the main function of the glutamatergic neurons of the basal forebrain is to receive some of the ascending input and transmit this information to the MSDB via local short-range and medium-range connections. The exact manner in which these inputs are processed by the basal forebrain glutamatergic neurons will require future investigation.

\section{Clinical significance}

Theta oscillation is asssociated with higher brain function such as learning and memory ${ }^{[41]}$. The interruption of these oscillatory activities were implicated in neurodegenerative diseases such as Alzheimer's Disease $(\mathrm{AD})^{[42]}$, which the loss or atrophy of the cholinergic neurons are known ${ }^{[43]}$. Induction of theta oscillations in MSDB by nicotine suggests that nAChR may be a potential therapeutic target in AD treatment. Disorder in network oscillatory activity has also been documented in neuropsychological disorders such as schizophrenia, and the new NAChR agonists have recently been developed and demonstrated to be effective in the treatment of cognitive impairments associated with schizophrenia ${ }^{[44]}$. Therefore, this study has provided additional evidence to support clinical application of $\mathrm{nAChR}$ agonists in these neuropsychological disorders.

\section{Acknowledgements}

This work was supported by National Natural Science Foundation of China (grant № 31070938, № 81271422) and the UK Medical Research Council (grant № G0500823 ).

\section{Author contribution}

Cheng-biao LU designed and performed research; Chengzhang LI performed research; Zaineb HENDERSON performed immunohistochemistry experiments; Dong-liang LI analyzed data; Cheng-biao LU wrote the paper.

\section{References}

1 Stewart M, Fox SE. Do septal neurons pace the hippocampal theta rhythm? Trends Neurosci 1990; 13: 163-8.

2 O'Keefe J, Conway DH. Hippocampal place units in the freely moving rat: why they fire where they fire. Exp Brain Res 1978; 31: 573-90.

3 Manns JR, Zilli EA, Ong KC, Hasselmo ME, Eichenbaum H. Hippocampal CA1 spiking during encoding and retrieval: relation to theta phase. Neurobiol Learn Mem 2007; 87: 9-20.

4 Hallanger $\mathrm{AE}$, Wainer $\mathrm{BH}$. Ascending projections from the pedunculopontine tegmental nucleus and the adjacent mesopontine tegmentum in the rat. J Comp Neurol 1988; 274: 483-515.

5 Nowacka A, Jurkowlaniec E, Trojniar W. Microinjection of procaine into the pedunculopontine tegmental nucleus suppresses hippocampal theta rhythm in urethane-anesthetized rats. Brain Res Bull 2002; 58: 377-84.

6 Vertes RP, Kocsis B. Brainstem-diencephalo-septohippocampal systems controlling the theta rhythm of the hippocampus. Neuroscience 1997; 81: 893-926.

7 Gogolak G, Petsche H, Sterc J, Stumpf C. Septum cell activity in the rabbit under reticular stimulation. Brain Res 1967; 5: 508-10.

8 Sweeney JE, Lamour Y, Bassant MH. Arousal-dependent properties of medial septal neurons in the unanesthetized rat. Neuroscience 1992; 48: 353-62.

9 Buzsaki G. Theta oscillations in the hippocampus. Neuron 2002; 33: 325-40.

10 Henderson Z, Jones GA. GABAB receptors in the medial septum/ diagonal band slice from 16-25 day rat. Neuroscience 2005; 132 : 789-800.

11 Garner HL, Whittington MA, Henderson Z. Induction by kainate of theta frequency rhythmic activity in the rat medial septum-diagonal band complex in vitro. J Physiol 2005; 564: 83-102.

12 Manseau F, Danik M, Williams S. A functional glutamatergic neurone network in the medial septum and diagonal band area. J Physiol 2005; 566: 865-84.

13 Goutagny R, Manseau F, Jackson J, Danik M, Williams S. In vitro activation of the medial septum-diagonal band complex generates atropine-sensitive and atropine-resistant hippocampal theta rhythm: an investigation using a complete septohippocampal preparation. Hippocampus 2008; 18: 531-5.

14 Wu M, Hajszan T, Leranth C, Alreja M. Nicotine recruits a local glutamatergic circuit to excite septohippocampal GABAergic neurons. Eur J Neurosci 2003; 18: 1155-68.

15 Henderson Z, Boros A, Janzso G, Westwood AJ, Monyer H, Halasy K. Somato-dendritic nicotinic receptor responses recorded in vitro from the medial septal diagonal band complex of the rodent. J Physiol 2005; 562: 165-82.

16 Wang $H$, Sun X. Desensitized nicotinic receptors in brain. Brain Res Brain Res Rev 2005; 48: 420-37.

17 Tamamaki N, Yanagawa Y, Tomioka R, Miyazaki J, Obata K, Kaneko T. Green fluorescent protein expression and colocalization with calretinin, parvalbumin, and somatostatin in the GAD67-GFP knock-in mouse. J Comp Neurol 2003; 467: 60-79.

18 Csicsvari J, Jamieson B, Wise KD, Buzsaki G. Mechanisms of gamma oscillations in the hippocampus of the behaving rat. Neuron 2003; 37: 311-22.

19 Moser N, Mechawar N, Jones I, Gochberg-Sarver A, Orr-Urtreger A, Plomann $\mathrm{M}$, et al. Evaluating the suitability of nicotinic acetylcholine receptor antibodies for standard immunodetection procedures. J Neurochem 2007; 102: 479-92.

20 Yamamoto A, Kiguchi N, Kobayashi Y, Maeda T, Ueno K, Yamamoto $\mathrm{C}$, et al. Pharmacological relationship between nicotinic and opioid 
systems in analgesia and corticosterone elevation. Life Sci 2011; 89: 956-61.

21 McQuiston AR, Madison DV. Nicotinic receptor activation excites distinct subtypes of interneurons in the rat hippocampus. J Neurosci 1999; 19: 2887-96.

22 Hormuzdi SG, Pais I, LeBeau FE, Towers SK, Rozov A, Buhl EH, et al. Impaired electrical signaling disrupts gamma frequency oscillations in connexin 36-deficient mice. Neuron 2001; 31: 487-95.

23 Palhalmi J, Paulsen O, Freund TF, Hajos N. Distinct properties of carbachol- and DHPG-induced network oscillations in hippocampal slices. Neuropharmacology 2004; 47: 381-9.

24 Thinschmidt JS, Frazier CJ, King MA, Meyer EM, Papke RL. Medial septal/diagonal band cells express multiple functional nicotinic receptor subtypes that are correlated with firing frequency. Neurosci Lett 2005; 389: 163-8.

25 Konopacki J, Bland BH, Roth SH. Evidence that activation of in vitro hippocampal theta rhythm only involves muscarinic receptors. Brain Res 1988; 455: 110-4.

26 Borhegyi Z, Varga V, Szilagyi N, Fabo D, Freund TF. Phase segregation of medial septal GABAergic neurons during hippocampal theta activity. J Neurosci 2004; 24: 8470-9.

27 Vinogradova OS, Brazhnik ES, Karanov AM, Zhadina SD. Neuronal activity of the septum following various types of deafferentation. Brain Res 1980; 187: 353-68.

28 Thinschmidt JS, Kinney GG, Kocsis B. The supramammillary nucleus: is it necessary for the mediation of hippocampal theta rhythm? Neuroscience 1995; 67: 301-12.

29 Kirk IJ. Frequency modulation of hippocampal theta by the supramammillary nucleus, and other hypothalamo-hippocampal interactions: mechanisms and functional implications. Neurosci Biobehav Rev 1998; 22: 291-302.

30 Karavaev EN, Popova IY, Kichigina VF. The nicotinic receptor blocker hexamethonium alters neuronal responses to glutamate in the medial septal area of the brain of the ground squirrel in vitro. Neurosci Behav Physiol 2008; 38: 297-307.

31 Manseau F, Goutagny R, Danik M, Williams S. The hippocamposeptal pathway generates rhythmic firing of GABAergic neurons in the medial septum and diagonal bands: an investigation using a complete septohippocampal preparation in vitro. J Neurosci 2008; 28: 4096-107.

32 Leranth C, Kiss J. A population of supramammillary area calretinin neurons terminating on medial septal area cholinergic and lateral septal area calbindin-containing cells are aspartate/glutamatergic. J Neurosci 1996; 16: 7699-710.
33 Borhegyi Z, Magloczky Z, Acsady L, Freund TF. The supramammillary nucleus innervates cholinergic and GABAergic neurons in the medial septum-diagonal band of Broca complex. Neuroscience 1998; 82: 1053-65.

34 Kiss J, Csaki A, Bokor H, Shanabrough M, Leranth C. The supramammillo-hippocampal and supramammillo-septal glutamatergic/ aspartatergic projections in the rat: a combined $\left[{ }^{3} \mathrm{H}\right] \mathrm{D}$-aspartate autoradiographic and immunohistochemical study. Neuroscience 2000; 97: 657-69.

35 Phelan KD, Sacaan A, Gallagher JP. Retrograde labeling of rat dorsolateral septal nucleus neurons following intraseptal injections of WGA-HRP. Synapse 1996; 22: 261-8.

36 Risold PY, Swanson LW. Connections of the rat lateral septal complex. Brain Res Brain Res Rev 1997; 24: 115-95.

37 Consolo S, Bertorelli R, Forloni GL, Butcher LL. Cholinergic neurons of the pontomesencephalic tegmentum release acetylcholine in the basal nuclear complex of freely moving rats. Neuroscience 1990; 37 : 717-23.

38 Fremeau RT, Jr., Troyer MD, Pahner I, Nygaard GO, Tran CH, Reimer RJ, et al. The expression of vesicular glutamate transporters defines two classes of excitatory synapse. Neuron 2001; 31: 247-60.

39 Lin W, McKinney K, Liu L, Lakhlani S, Jennes L. Distribution of vesicular glutamate transporter-2 messenger ribonucleic Acid and protein in the septum-hypothalamus of the rat. Endocrinology 2003; 144: 662-70.

40 Hajszan T, Alreja M, Leranth C. Intrinsic vesicular glutamate transporter 2-immunoreactive input to septohippocampal parvalbumincontaining neurons: novel glutamatergic local circuit cells. Hippocampus 2004; 14: 499-509.

41 Olvera-Cortes ME, Garcia-Alcantar I, Gutierrez-Guzman B, HernandezPerez JJ, Lopez-Vazquez MA, Cervantes M. Differential learningrelated changes in theta activity during place learning in young and old rats. Behavioural brain research 2012; 226: 555-62.

42 Colom LV, Castañeda MT, Bañuelos C, Puras G, García-Hernández A, Hernandez S, et al. Medial septal $\beta$-amyloid 1-40 injections alter septo-hippocampal anatomy and function. Neurobiology of aging 2010; 31: 46-57.

43 Whitehouse PJ, Price DL, Struble RG, Clark AW, Coyle JT, Delon MR. Alzheimer's disease and senile dementia: loss of neurons in the basal forebrain. Science 1982; 215: 1237-9.

44 Tregellas JR, Tanabe J, Rojas DC, Shatti S, Olincy A, Johnson L, et al. Effects of an alpha 7-nicotinic agonist on default network activity in schizophrenia. Biol Psychiatry 2011; 69: 7-11. 